\title{
Cenlestao
}

\section{Desinformação e informação semântica: a Filosofia da Informação e o pensamento de Luciano Floridi na contribuição à confiabilidade informacional ${ }^{1}$}

\author{
Leonardo Ripoll \\ Mestre; Universidade Federal de Santa Catarina, Florianópolis, SC, Brasil; \\ leonardo_ripoll@hotmail.com \\ José Claudio Morelli Matos \\ Doutor; Universidade do Estado de Santa Catarina, Florianópolis, SC, Brasil; \\ doutortodd@gmail.com
}

\begin{abstract}
Resumo: O artigo apresenta, de forma introdutória, a Filosofia da Informação, abordagem teórico-metodológica desenvolvida por Luciano Floridi como uma fundamentação epistemológica adequada à sociedade da informação, termo proposto como representativo do atual cenário socio-histórico. Por meio de um estudo com características exploratórias, discute conceitos cruciais do pensamento de Floridi, como informação semântica e veridicalidade da informação, para demonstrar como esse pensamento trata da questão da desinformação. Relaciona, por fim, as ideias de Floridi com a noção de 'confiabilidade informacional', conceito a ser desenvolvido no contexto contemporâneo visando ao combate à desinformação.
\end{abstract}

Palavras-chave: Filosofia da informação. Luciano Floridi. Informação semântica. Desinformação. Confiabilidade informacional.

\section{Introdução}

O surgimento da chamada sociedade da informação tem trazido novas formas de pensar sobre as atividades humanas e sua relação com a informação e o conhecimento. Como Castells (1999) indica, há uma transição do industrialismo para um informacionalismo, proveniente principalmente do desenvolvimento das Tecnologias de Informação e Comunicação (TIC). Luciano Floridi (2010b) afirma que, por meio da revolução da informação, as TIC promoveram uma nova organização da sociedade, que passou a funcionar em torno de serviços e produtos informacionais. 
Essa reorganização social tem promovido, por sua vez, uma reorganização do conhecimento, através da proposição de novas metodologias, assim como de uma base ontológica e epistemológica reformulada. Uma destas novas propostas para tentar entender o atual estágio do desenvolvimento cultural da humanidade é a que Floridi (2020b, 2011, 2002) denominou de Filosofia da Informação.

É possível perceber, entre alguns pesquisadores, certo otimismo em relação à configuração cultural e social ocasionada pelas tecnologias digitais, como é o caso de Pierre Lévy (2010), ao desenvolver a sua concepção de cibercultura. Contudo, não se devem negligenciar os dilemas e impasses que essa ordem social acarreta, justamente em torno da ideia de acesso à informação e disseminação da informação e suas implicações éticas e políticas. Armand Mattelart (2005, p. 5), em conferência intitulada Sociedade do conhecimento e controle da informação e da comunicação, afirma muito oportunamente que "a história da idéia [sic] e da noção de 'sociedade da informação' é sinuosa e cheia de ambigüidades [sic].”. Tais ambiguidades fazem ressaltar as desigualdades de participação de grande parcela da população no emprego da tecnologia informacional, assim como o problema da vigilância e da invasão da vida íntima das pessoas.

Entre tais questões, o presente estudo espera pôr em destaque o tema da desinformação, associado à urgente necessidade de estabelecer critérios seguros de confiabilidade adequados à vida na sociedade da informação. A proposta deste artigo é, assim, apresentar, de forma introdutória, o pensamento de Luciano Floridi - em especial sua Filosofia da Informação, interpretada em primeiro lugar como uma epistemologia voltada à sociedade da informação, mas também como uma base teórica possível na busca pela confiabilidade informacional.

O artigo lançou mão como metodologia de pesquisa bibliográfica da filosofia de Luciano Floridi e de seus trabalhos em filosofia da informação, sobretudo naqueles de caráter introdutório aos conceitos desenvolvidos pelo autor. A pesquisa se caracteriza pela natureza exploratória, conforme definição proposta, por exemplo, por autores como Cervo, Bervian e Silva (2007). A 
natureza exploratória da pesquisa se evidencia no duplo movimento de familiarizar-se com os conceitos e com a obra de Floridi e, assim, de obter novas ideias e percepções ainda não formuladas. A pesquisa também envolveu buscas sobre o autor nas publicações brasileiras do campo da Ciência da Informação. Para tanto, as estratégias de busca envolveram filtrar apenas documentos em português e usar as palavras Floridi e filosofia da informação, de forma combinada ou isolada. Tal averiguação foi realizada por meio da Base de Dados Referencial de Artigos de Periódicos em Ciência da Informação (BRAPCI), da Library \& Information Science Abstracts (LISA) e do Portal de Periódicos da CAPES.

Os documentos recuperados pela pesquisa bibliográfica, além das produções originais do próprio Floridi, foram analisados seguindo o procedimento da leitura crítica, a fim de identificar e avaliar os argumentos, os conceitos e as relações de interação. Os resultados de tal análise e as conclusões obtidas compõem a estrutura do presente artigo.

\section{Luciano Floridi e a Filosofia da Informação}

A Filosofia da Informação proposta por Luciano Floridi busca uma retomada dos princípios epistemológicos do conceito de informação, que, apesar de há muito tempo utilizado e conhecido, ganhou novas significações e maior alcance a partir da emergência do que se convencionou chamar de sociedade da informação.

Ainda que se possa questionar se, de fato, a sociedade da informação exista enquanto fenômeno que engloba a maioria da população mundial, com a utilização do termo visa-se, sobretudo, manter a coerência com o vocabulário e a narrativa desenvolvidos por Floridi. Segundo o autor, a sociedade da informação, como é entendida atualmente, está relacionada ao fato de que o progresso e o bem-estar humanos dependem de exitosas gestões de processos, serviços e questões que envolvem a informação para serem alcançados. Floridi (2010b) afirma, por exemplo, que 70\% do Produto Interno Bruto (PIB) dos países membros do G7 (Estados Unidos, Canadá, França, Alemanha, Itália, Japão e Reino Unido) dependem de bens intangíveis relacionados à informação, 
o que os acaba qualificando, de fato, como exemplos autênticos de sociedades da informação.

Os dilemas advindos do impacto produzido pela sociedade da informação, portanto, demandam um reposicionamento do papel do saber e da própria identidade humana, nesse contexto de produção e expansão contínua de dados e informação. Como compara Floridi (2010b, p. 7, tradução nossa),

A sociedade da informação é como uma árvore cujos ramos de longo alcance vêm crescendo muito mais amplamente, apressadamente e caoticamente do que suas raízes conceituais, éticas e culturais. ${ }^{2}$

Ou seja, Floridi não ignora a necessidade de cuidadoso tratamento crítico de todas as consequências dessa configuração social. Para equilibrar essa árvore e impedir o seu colapso, o autor salienta a urgência de a sociedade se equipar epistemologicamente com uma viável filosofia da informação,

[...] a fim de expandir e reforçar a nossa compreensão conceitual da nossa era da informação, da sua natureza, das suas implicações menos visíveis e do seu impacto no bem-estar humano e ambiental, e assim dar-nos a oportunidade de antecipar dificuldades, identificar oportunidades e resolver problemas. (FLORIDI, 2010b, p. 8, tradução nossa). ${ }^{3}$

O termo Filosofia da Informação foi cunhado por Luciano Floridi, professor e pesquisador da Universidade de Oxford, Inglaterra. Tendo usado esse termo pela primeira vez em uma série de papers em 1996, Floridi escreveu o seu principal artigo sobre o tema em 2002, com o título de What is the philosophy of information? (FLORIDI, 2002). Desde então, Floridi tem trabalhado no desenvolvimento da Filosofia da Informação como uma nova e independente área de pesquisa (FLORIDI, 2020b).

Ainda que o próprio Floridi apresente o termo como uma formulação original, é importante ressaltar que discussões sobre o tema já existiam antes de o autor surgir, principalmente nos trabalhos pioneiros de Norbert Wiener, Claude Shannon e Warren Weaver e mais recentemente na obra de Fred Dretske e Terrence Deacon. Informação é um tema recorrente no pensamento teórico e filosófico a partir da metade do século XX, e a alegada originalidade de Floridi tem, de fato, que ser reduzida a proporções mais modestas. Contudo, no 
movimento cultural disto a que Frederick Adams (2003) chama de virada informacional, é preciso reconhecer que a contribuição de Floridi é tanto relevante como original na forma de abordagem, no repertório de termos e conceitos e nas implicações que acarreta para a confiabilidade e o combate à desinformação, tratadas ao final do artigo.

Luciano Floridi nasceu em Roma, Itália, onde fez sua graduação. Logo em seguida, cursou o mestrado, o doutorado e o pós-doutorado em Filosofia, na Universidade Warwick e na Universidade de Oxford. Em Oxford, Floridi começou a trabalhar como professor e pesquisador no início dos anos 1990, dentro do departamento de Ciência da Computação. Atualmente, é professor de Filosofia e Ética da Informação e diretor do Laboratório de Ética Digital (Digital Ethics Lab), em Oxford. Participa também do Exeter College e do Data Ethics Group, dentro do Alan Turing Institute, e atua como professor adjunto na American University, nos Estados Unidos. Possui mais de 150 artigos publicados e traduzidos para mais de 15 idiomas e já recebeu diversos prêmios e menções de reconhecimento pelo desenvolvimento de seu trabalho, além de ter sido membro de uma série de grupos e comitês. Suas pesquisas concentram-se, principalmente, nos seguintes tópicos: Ética Digital, Filosofia da Informação e Filosofia da Tecnologia, Epistemologia, Filosofia da Lógica, e História e Filosofia do Ceticismo (FLORIDI, 2020a).

Segundo Floridi (2020b), seu principal projeto é a tetralogia envolvida na fundação da Filosofia da Informação, chamada Principia philosophiae informationis, e composta pelos livros: The philosophy of information (primeiro volume, 2011), The ethics of information (segundo volume, 2013), The logic of information (terceiro volume,2019) e The politics of information (quarto volume, prestes a ser publicado). Além disso, o autor publicou mais dois livros introdutórios ao tema: Information: a very short introduction (2010) e The fourth revolution: how the infosphere is reshaping human reality (de 2014). As relações entre as obras são apresentadas na figura 1: 
Figura 1 - Principia Philosophiae Informationis de Luciano Floridi

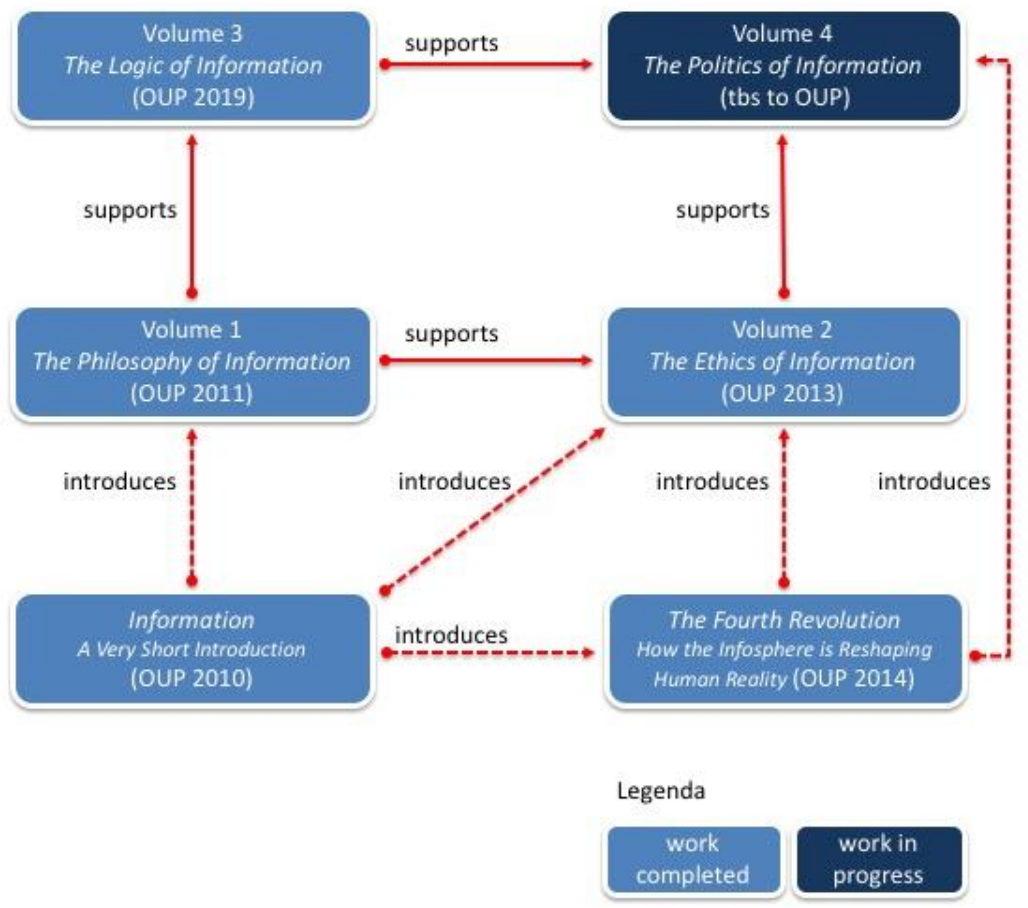

Fonte: Floridi (2020b, p. 1).

Floridi (2020b) acredita que a informação é um conceito tão fundamental e importante quanto os conceitos de verdade, significado, conhecimento, ser, e bem e mal. Além disso, o autor afirma que informação é um conceito que carece de um significado sólido e distinto quando tomado individualmente. Como o conceito de informação é geralmente utilizado em diferentes campos de discussão científica (muitas vezes sem relação próxima entre os diversos usos do termo), muitos desses campos empregam a noção de informação como uma forma de organizar a investigação de outros conceitos. Portanto, para este autor, o conceito de informação merece uma investigação filosófica autônoma, a fim de definir criteriosamente seu escopo.

Segundo Floridi (2020b), a revolução informacional em curso tem transformado o mundo de forma rápida, irreversível e profunda, fazendo com que a criação, o gerenciamento e a utilização da informação sejam questões vitais para a atual sociedade. Da mesma forma, essa revolução trouxe novos desafios para a filosofia e para o conhecimento como um todo. Assim, a Filosofia da Informação precisa dar conta desses desafios, que envolvem o 
tratamento de conceitos e fenômenos apresentados pela revolução informacional, para então permitir um desenvolvimento consciente e responsável da sociedade da informação.

De acordo com Floridi (2002), o surgimento conceitual da Filosofia da Informação vem, primeiramente, de um processo histórico e reflexivo acerca da vida mental do indivíduo, ao tentar gerar significados perante o mundo. Esse processo, chamado pelo autor de dialética da reflexão, advém de quatro empurrões (thrusts) iniciais: a metassemantização das narrativas (reconhecimento do pensar), a delimitação da cultura (comunicar), a desfisicalização da natureza (significar) e a personificação do ambiente conceitual criado e habitado pela mente (explicar). Como consequência disso, o autor entende que:

[...] a sociedade da informação pode ser vista como o mais recente (ainda que não definitivo) estágio em um amplo processo semântico que faz com que o mundo mental seja cada vez mais parte, ou o próprio ambiente em que mais e mais pessoas tendem a viver. (FLORIDI, 2002, p. 131, tradução nossa). ${ }^{4}$

A espécie humana define seu modo de ser por meio de uma modificação do ambiente em que habita. Esta ideia não é nova. O que há de original na teoria de Floridi sobre a semantização do ser é que, na história humana, sua relação com o mundo se faz pela construção de significados e de entidades que carregam estes significados, como os casos da linguagem escrita, da imprensa e dos livros e, atualmente, do ciberespaço. Em outras palavras, a sociedade da informação é o meio caracterizado pelas ações e criações do aparelho cognitivo humano (como a história e a cultura), enquanto o mundo físico (a natureza) é considerado o pano de fundo do processo de desenvolvimento social (FLORIDI, 2002). O ser humano, portanto, vive de produzir e empregar símbolos para transmitir informações, para organizar a experiência social e individual na forma de narrativas carregadas de atribuições de valor e de crenças e, finalmente, para moldar um mundo de artefatos que acolhem e processam automaticamente esse montante de cultura produzido pela humanidade. Essa é a descrição de um processo acumulativo e gradual, cujo ponto culminante até o momento é a atual sociedade da informação. 
Floridi (2002) explica que as inovações filosóficas sempre vieram de uma ruptura com a atitude escolástica (compreendida aqui, de forma simples, como a afirmação enfática do que está estabelecido enquanto conhecimento validado e vigente), causada por alguma força social externa no progresso semântico humano. Por meio da atuação dessas forças de mudança, a cristalização da cultura e do conhecimento na forma escolástica dá lugar a possibilidades de inovação e mudança. Floridi (2002) cita, como exemplos de forças externas que causaram mudanças de paradigma, a teologia cristã, a descoberta de outras civilizações, a revolução científica, a teoria da evolução por seleção natural, a teoria da relatividade, entre outros.

De acordo com o autor, a atual força externa que conduz à inovação e a uma nova forma de conhecimento é o complexo organizado de fenômenos da informação e da comunicação, constituído por suas correspondentes ciências e tecnologias, por seus novos ambientes e vida social e por suas novas questões existenciais e culturais. Dentro desse contexto, o autor propõe a Filosofia da Informação como um ponto de vista inovador (ainda que se possa questionar o quanto de originalidade sua teoria realmente tem).

Floridi (2002, p. 137, tradução nossa, grifo nosso) assim define a Filosofia da Informação:

[...] o campo filosófico interessado por (a) uma investigação crítica sobre a natureza conceitual e os princípios básicos da informação, incluindo suas dinâmicas, utilização, e ciências, e (b) a elaboração e aplicação da teoria informacional e metodologias computacionais para os problemas filosóficos. ${ }^{5}$

Floridi (2020b) também comenta que a Filosofia da Informação investiga as consequências éticas da informação e "Analisa problemas para projetar soluções. É uma próspera área de pesquisa, na encruzilhada da epistemologia,

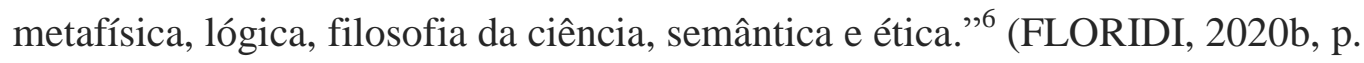
1, tradução nossa). De fato, os temas relacionados à informação vêm ganhando importância enquanto alvos da reflexão filosófica. Bem assim, pode-se observar, através de um exame das recentes publicações, que as diversas áreas da filosofia, assim como de outras ciências relacionadas, vêm dedicando cada vez 
mais energia à compreensão dos fenômenos informacionais. Sabe-se que Floridi não é único na proposta de métodos de abordagem que incluam a informação na agenda da filosofia. Sua singularidade reside, possivelmente, no grau de profundidade e objetividade com que trata do tema da informação e na proposta de uma fundamentação conceitual elaborada exclusivamente para seu tratamento. $\mathrm{O}$ autor complementa:

Sobre o seu ambiente, a Filosofia da Informação é determinante e legisla sobre o que pode ser contado como informação e como a informação deve ser adequadamente criada, processada, gerenciada e usada. (FLORIDI, 2002, p. 138, tradução nossa). ${ }^{7}$

Sendo assim, Floridi (2002, p. 137, tradução nossa) define que a tarefa da Filosofia da Informação é justamente

[...] desenvolver não uma teoria unificada da informação, mas sim uma família integrada de teorias que analisam, avaliam e explicam os vários princípios e conceitos de informação, suas dinâmicas e utilização, com uma atenção especial para questões sistêmicas que emergem de diferentes contextos de aplicação e interconexões com outros conceitos chave na filosofia, como o ser, o conhecimento, a verdade, a vida, e o significado. ${ }^{8}$

Dessa forma, a Filosofia da Informação destina-se a interpretar e validar a natureza da informação. Além dessa parte de fundamentação, a Filosofia da Informação também constitui uma diretriz metodológica, dado que um problema ou uma explicação tradicional em filosofia podem ser formulados em termos informacionais.

Há que se considerar, no entanto, que a relevância de Floridi para os estudos sobre a informação está interligada também ao contexto de surgimento dos seus trabalhos. Filosofar a informação, como já se disse, não é uma iniciativa recente. Porém, o desenvolvimento que a computação e as TIC tiveram a partir dos anos 1990 e, principalmente, após a expansão da internet e a ocupação do seu ciberespaço, como propõe Lévy (2010), trouxe novas demandas de discussão do conhecimento e da sociedade que o cria. Se Floridi aparece como um autor representativo de seu tempo, é porque o seu trabalho demonstra função dicotômica e complementar: é relevante pela elaboração sistemática de suas ideias, mas também é pertinente por surgir em um momento oportuno a tal tipo de discussão. Além disso, é gerido num terreno que ainda 
estava por fertilizar, devido ao efeito dos estudos das décadas anteriores. Filosofar a informação é, assim, uma tendência da filosofia contemporânea.

Posteriormente, dando continuidade ao seu artigo inicial, Floridi (2011) identificou dezoito problemas vitais para a Filosofia da Informação, divididos em cinco grandes áreas, dos quais, de forma adaptada, se citam alguns:

a) sobre a análise do conceito de informação: O que é informação? Quais são as dinâmicas da informação? É possível uma teoria unificada da informação?;

b) sobre a semântica: Como os dados adquirem significado? Como um dado com conteúdo adquire o valor de verdadeiro? A informação pode explicar a verdade? A informação pode explicar o significado?;

c) sobre o estudo da inteligência: As formas de inteligência natural podem ser totalmente implementadas artificialmente de forma satisfatória? Uma abordagem informacional resolve os problemas do dualismo cartesiano? A epistemologia pode ser baseada em uma teoria da informação? Como a informação pode ser avaliada? A ciência é redutível a um modelo informacional?;

d) sobre a relação entre informação e natureza: Qual é o status ontológico da informação? A informação pode ser naturalizada? A natureza pode ser informacionalizada?;

e) sobre a investigação de valores: A ética referente às TIC tem uma base filosófica?

Tais indagações definem grande parte do corpus da Filosofia da Informação e sua metodologia de trabalho. Para Floridi (2002), a Filosofia da Informação, entendida como a mais recente philosophia prima, é a nova etapa do processo de semantização do ser - sua forma mais atualizada e completa de entender o mundo e a sociedade. A origem da Filosofia da Informação, então, engloba os variados contextos presentes no atual paradigma informacional.

Desde a sua criação, a Filosofia da Informação de Floridi tem sido objeto de discussão por vários pesquisadores. Porém, dentro da área da Ciência da Informação brasileira, encontram-se ainda alguns poucos trabalhos, como os de 
Suave e Albuquerque (2018), Leite e Matos (2017), Lima e Gomes (2016), Revoredo (2015, 2014), Gonzalez de Gómez (2017, 2013), Salcedo e Revoredo (2013), Rabello (2013), Robredo (2011), Saldanha (2011), Mostafa (2010), Matheus (2005) e Francelin e Pellegatti (2004), que mencionam diretamente o termo 'Filosofia da Informação' e o nome de Luciano Floridi'. Apesar disso, nota-se um crescente interesse no tema desenvolvido pelo autor, pois dos quatorze documentos encontrados, doze foram produzidos a partir do ano de 2010.

Salcedo e Revoredo (2013, p. 11-12), por exemplo, definem que

[...] a Filosofia da Informação é uma área de estudo em formação que observa a informação em seus diversos níveis. Admite sua intrínseca relação com a sociedade, mesmo esta fazendo uso da informação por meios técnicos e não reflexivos. Aborda a informação enquanto perspectiva de futuro, observando a evolução das novas Tecnologias de Informação e Comunicação e, como se pode observar e estruturar configurações teóricas para informação. A Filosofia da Informação configura-se como campo da pesquisa filosófica voltado para a investigação crítica da estrutura conceitual das elaborações e aplicações da teoria da informação e das metodologias computacionais aos problemas filosóficos, pressupõe que um problema ou uma explicação pode ser legitimamente e genuinamente reduzido para um problema informacional.

A Filosofia da Informação também parece disputar cenário com a própria epistemologia da Ciência da Informação. De acordo com Salcedo e Revoredo (2013, p. 2),

A informação, enquanto conteúdo ganhou novas análises em relação a sua propagação e formas de inserção social, passou a ser estudada numa abordagem reflexiva, embasada na Ciência da Informação e na própria Filosofia.

Portanto, dentro do fenômeno da sociedade da informação, ou da quarta revolução/revolução informacional de Floridi (2010b), a informação não é mais apenas uma ferramenta para a obtenção do conhecimento, ela torna-se a base da discussão acerca de tudo que movimenta a sociedade atualmente.

Para Francelin e Pellegatti (2004, p. 130),

Como objeto 'mutante', a informação em sua pluralidade conceitual está à espera de uma abordagem filosófica que possa contribuir para a revisão e constituição de teorias no campo da Ciência da Informação. 
Ou seja, a demanda epistemológica da Ciência da Informação parece levar seus praticantes a buscar uma definição filosófica robusta da informação, que possibilite a demarcação precisa de seu campo.

Souza (1986), em um texto da década de 1980 denominado Fundamentos filosóficos da Biblioteconomia, já apresentava algumas problematizações sobre a tecnicidade da Biblioteconomia, visando a que ela se tornasse, de fato, uma ciência, a partir de uma investigação filosófica e epistemológica. Segundo o autor, a Ciência da Informação seria, então, entendida na época como a própria Filosofia da Biblioteconomia.

A relação da Biblioteconomia e da Ciência da Informação, as quais Floridi (2010a) abrevia como BCI, com a Filosofia da Informação não poderia ser mais óbvia, pois todas possuem o mesmo objeto de estudo. Floridi (2010a) apresenta, inclusive, uma proposta de entender a BCI como Filosofia da Informação aplicada. $\mathrm{O}$ autor constitui seu argumento na base de uma crítica à chamada epistemologia social, que segundo ele encontra grande aceitação na comunidade de estudiosos da área. Sua proposta é que a Filosofia da Informação, como fundamento epistemológico da BCI, permite maiores desenvolvimentos para o campo e uma base mais sólida e consistente em termos conceituais (FLORIDI, 2010a). No entanto, tal arguição é encarada com consideráveis críticas e ressalvas, como as de Cornelius (2004), que compreende a visão de Floridi sobre a Ciência da Informação como um tanto inocente e superficial e sua proposta de Filosofia da Informação como afastada das práticas dos indivíduos ou de seus recipientes informacionais.

Entre as questões levantadas por Floridi (2011) dentro de sua filosofia, estão suas preocupações sobre a validade da informação. Para o autor, é importante determinar um sentido técnico do conceito de informação. $\mathrm{Na}$ medida em que serve como um critério para julgar a informação, esse conceito guarda relação com processos que estabeleceriam o grau de confiança que se está justificado em depositar nessa informação.

O projeto de Floridi celebra um significado muito caro para a tradição do que seja a filosofia. Com o avanço e o desdobramento de diversos campos das ciências particulares, especialmente nos últimos cem anos, a filosofia vem se 
abstendo da tarefa de explicar o funcionamento do mundo e de suas entidades, dando espaço para que o método científico cumpra esse papel. Fica reservada para a fillosofia uma tarefa de elaboração e interpretação dos conceitos, além de um trabalho de questionamento e crítica, sob o método da argumentação. Nessa direção se move Floridi, quando espera satisfazer a exigência, que ele mesmo formula, de uma filosofia da informação que se constitua de forma íntegra e sistemática, aproveitando as realizações da ciência, mas também se dirigindo a essas realizações com olhar crítico.

\subsection{Informação semântica, veridicalidade e confiabilidade da informação}

A noção de confiabilidade ${ }^{10}$ é explorada por Floridi (2011) em sua discussão sobre o que ele chama de informação semântica e sua tese da veridicalidade (veridicality thesis).

Floridi $(2011,2010 b)$ parte de um conceito de informação que é muito difundido em áreas que trabalham diretamente com ela: aquele que relaciona informação com dados bem formados (sintaxe) e significativos (semântica). Tal conceito promove a formulação de uma Definição Geral de Informação (DGI). Apesar de reconhecer a utilidade prática da DGI, Floridi (2011) argumenta que tal definição não basta para discussões epistemológicas sobre a informação. O grande problema da DGI provém de sua neutralidade a respeito de valores da informação relacionados à verdade, pois a DGI acaba englobando a falsa informação (desinformação) no escopo de seu conceito. Ou seja, podem-se ter dados bem formados e significativos, mas que, sob um exame mais aproximado, se revelam falsos. Assim sendo, informação falsa ainda assim seria informação, e a promoção ou disseminação de informação falsa poderia ser considerada uma atitude informativa.

Um dos pressupostos para o combate ou proteção das pessoas e grupos sociais contra o avanço da desinformação é a diferenciação entre a informação legítima e a falsa informação, ou má informação. Por isso, o conceito de informação, sendo rigoroso a este ponto, jamais poderia permitir a inclusão de informação falsa em seu escopo. A definição que Floridi (2011) dá para a informação semântica é, assim, uma correção e crítica à DGI, pois não basta que 
os dados sejam bem formados e significativos: eles também precisam ser confiáveis (truthful) ${ }^{11}$. E a confiança, por sua vez, é uma relação que se estabelece entre o ser humano de um lado e a informação verdadeira de outro. Não faria sentido confiar no que é falso, e sim apenas no que tem a potencialidade de ser verdadeiro.

Nesse sentido, quando Floridi (2011) utiliza a palavra semântica junto com informação, também está querendo dizer que a informação que está preocupado em definir é a informação declarativa, que se refere a um fato (que o autor também chama de factual), e assim avaliável como verdadeira ou falsa.

Uma descrição de um estado de coisas, uma explicação científica, uma notícia são casos de discurso denotativo, nestes termos. Já um arquivo de música, uma pintura, uma instrução, uma prece, uma ordem, um convite ou um discurso conotativo qualquer são exemplos de informação que estão fora de um possível julgamento de veracidade epistêmica.

No entanto, Floridi parece variar nos termos que utiliza para a informação que ele quer definir, em relação à sua veracidade, como objeto de análise: ora aparece como factual semantic information (FLORIDI, 2010b), ora apenas como semantic information (FLORIDI, 2011). Ademais, quando se refere ao semantic content, não está falando ainda da informação semântica que engloba a correção à DGI, pois como pode ser visto em seu mapa de conceitos (Figura 2), a desinformação também possui conteúdo semântico. Mesmo sendo falsa, a desinformação possui um significado que pode ser apreendido e interpretado. Aí reside seu aspecto mais perigoso, aliás, a confusão entre significatividade e verdade. 
Figura 2 - Mapa de conceitos informacionais

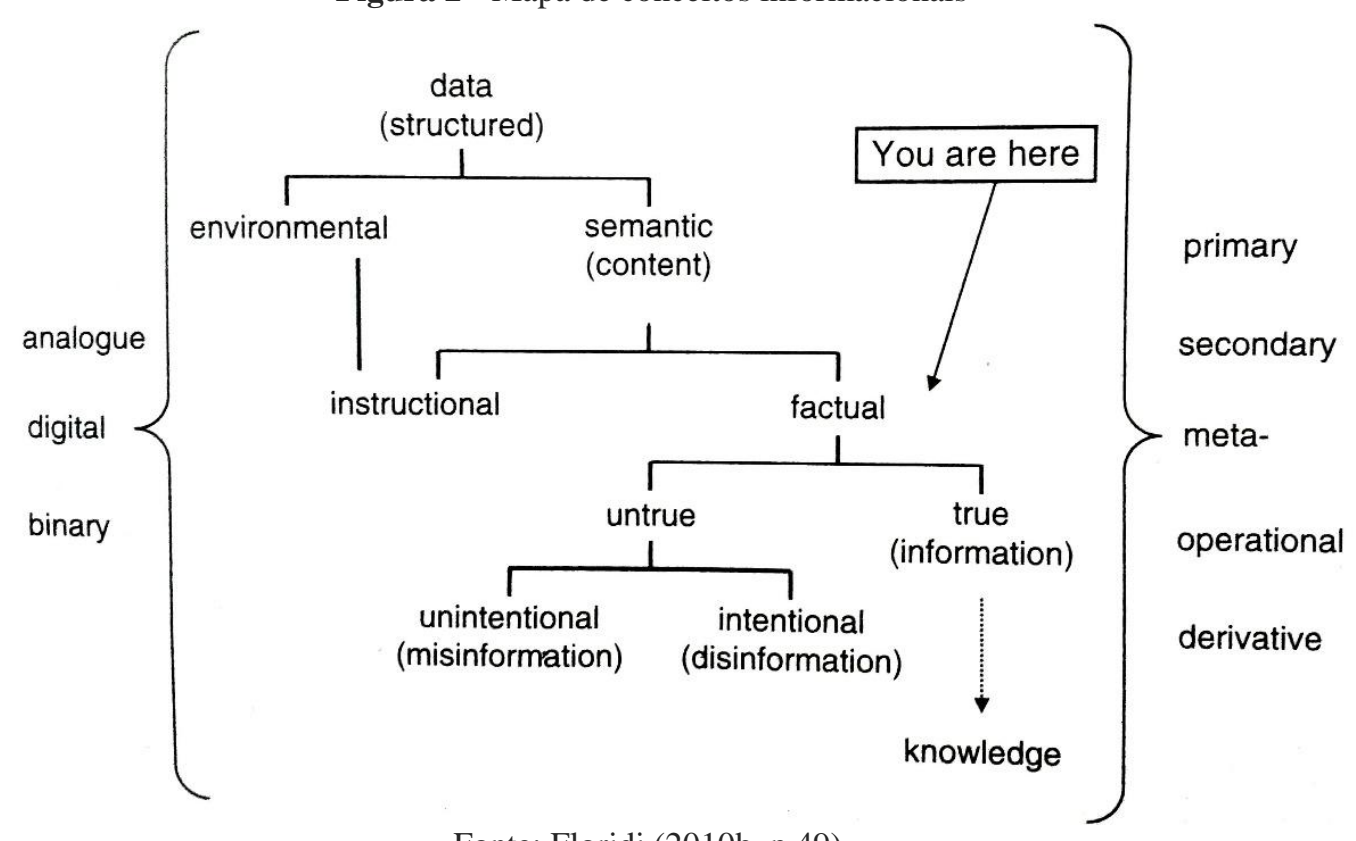

Fonte: Floridi (2010b, p 49).

Buscando esclarecer possíveis confusões conceituais, é preciso ressaltar que o conteúdo (content) é uma característica dos dados mesmo antes de ser informação, e é por isso que a desinformação possui conteúdo semântico (detém significado em um vocabulário), mas, por não ser verdadeira factualmente, não corresponde a uma informação semântica. Ou seja, não corresponde realmente a uma informação.

Assim, uma das principais consequências de uma definição de informação que inclui como critério o seu valor de verdade é qualificar a desinformação como não informação. Ou como Floridi (2011) argumenta: pseudoinformação.

Floridi (2011) ilustra com exemplos retóricos: assim como um pato de borracha não é um tipo de pato, um amigo falso não tem nada de amigo, a desinformação não pode ser informação. Se, em termos discursivos, uma mentira não é uma forma de contar a verdade, uma desinformação não pode ser informativa. Considerar desinformação como informação seria, portanto, concordar que a desinformação produz conhecimento e, dessa forma, tratar-se-ia de um conhecimento esquizofrênico, pois estaria distante da verdade e, portanto, distante da própria noção de realidade. Além disso, Floridi (2011) ressalta que não se deve confundir o conceito de informação com o de comunicação. 
Informar é diferente de comunicar, justamente porque a mentira é uma forma de comunicação, mas não de informação semântica.

Por isso, neste ponto de vista, um documento, por exemplo, compreende sempre uma mensagem inscrita em algum suporte e em alguma linguagem e está contextualizado também por certos usos sociais. Porém o documento pode conter ou não conter informação, dependendo da veracidade ou da falsidade de seu conteúdo. Se a tese da veridicalidade for admitida, e a DGI for atualizada nos termos da veridicalidade (tal como Floridi propõe), documentos cujo conteúdo semântico seja falso passam a ser considerados em desinformação.

O hábito da BCI de considerar todos os documentos sob a denominação geral de informação, transferindo a tarefa de discutir sua veracidade ou falsidade para as áreas específicas de conhecimento, mereceria, sob este ponto de vista, ser submetido a um exame crítico. Sob a definição de informação que Floridi propõe, uma parte significativa das mensagens ou documentos que circulam nas vias físicas ou virtuais da cultura humana não constituiriam de fato informação, e sim desinformação. Fica aqui instalado, portanto, nos termos da tese da veridicalidade de Floridi, um debate filosófico acerca da natureza informativa ou desinformativa dos documentos. Este debate tende a apontar vias muito interessantes de reflexão acerca da função social de campos da BCI tais como Recuperação da Informação, Organização do Conhecimento e Fontes de Informação. Em outras palavras: a tese da veridicalidade de Floridi parece uma contribuição substancial para o debate que envolve a função social da BCI porque, ao abrir a possibilidade de que nem todo documento seja considerado informação, retoma de maneira relevante e significativa a velha distinção entre informado e desinformado, para o caso dos usuários dos sistemas de informação dos quais trata a BCI.

Para justificar sua argumentação, Floridi (2011) utiliza uma análise sintática e outra semântica do conceito de informação falsa (false information), ou desinformação, aqui no sentido da má informação (misinformation), que resulta em uma negação da caracterização dela como informação. $\mathrm{O}$ autor argumenta que diferentemente, por exemplo, da informação digital (é digital e é 
informação), na informação falsa, a falsa é um modificador de negação do estado anterior. Resulta disso: é informação e é falsa, ou seja, não é informação.

Para Floridi (2011), a DGI está considerando a desinformação como informação também, pois os dados podem ser imprecisos e incorretos e, ainda assim, estarem bem formados e com significado. Uma desinformação só pode ser informativa de forma indireta ou derivada (por exemplo, ao informar a baixa confiabilidade da fonte), mas então, a questão passa a ser outra, que não o conteúdo informativo da própria mensagem informada.

A exigência de que os dados bem formados e significantes também sejam verdadeiros (ou confiáveis) é o que Floridi (2011) propõe como correção à DGI e como definição de informação semântica. Essa exigência está configurada na tese da veridicalidade/veracidade desenvolvida pelo autor. Por meio da tese, Floridi (2011) desenvolve o que chama de teoria da informação fortemente semântica, baseada em uma abordagem quantitativa da informação semântica, que faz a análise de níveis de veracidade (truth values) e discrepância semântica contidos em uma dada situação.

Floridi (2011) também comenta que a noção clássica de conhecimento como uma crença justificada e verdadeira também passa a ser percebida como possuidora da verdade, já que está incorporando a informação semântica. Podese, então, concluir que, consequentemente, não existe conhecimento falso e que informação falsa não gera conhecimento (novamente, apenas de forma derivativa ou indireta).

A preocupação com a verdade, como visto, é uma questão filosófica e epistêmica que se relaciona com a própria noção de realidade percebida pelo indivíduo e com a construção do conhecimento. A informação é o principal elemento presente nesse processo de construção e, mais do que nunca, a grande representante da atual realidade.

Se “[...] estar informado [...] implica reter algo verdadeiro." (FLORIDI, 2011, p. 96, tradução nossa), então uma consistente distinção do que é verdadeiro ou falso dentro do contexto informacional contemporâneo é, em última instância, uma análise do que realmente é informação dentro da sociedade da informação. 
Mas então, se ela não está em todas as partes, onde realmente está a informação? Como identificar a informação que contém a verdade? Propõe-se, nesse sentido, que se estruture uma busca pela confiabilidade informacional, obtida por meio da análise crítica das informações, como desenvolvido em Leite (2018).

A confiabilidade se fundamenta, acima de tudo, em exercer a interpretação crítica das mensagens a fim de julgar sua veridicalidade. Pois, se o exercício crítico da razão é o principal meio para chegar ao conhecimento, ele também é o método para discernir quais os caminhos que levam até lá. $O$ julgamento individual ancorado em evidências é, portanto, a última linha de defesa contra a disseminação da desinformação.

\section{Considerações finais}

A Filosofia da Informação e as pesquisas de Luciano Floridi apresentam importantes questões sobre a forma de lidar com a informação e o conhecimento dentro da sociedade da informação do século XXI. Seu trabalho não só impacta a epistemologia e a filosofia, mas também tem relevância dentro da Ciência da Informação. Ainda que tenham sido encontradas poucas publicações sobre o autor dentro da Ciência da Informação brasileira, a tendência parece ser que, gradualmente, ele seja difundido e incorporado nas discussões de todas as áreas de que participam os profissionais da informação.

Sobretudo para lidar com o atual cenário da desinformação (e suas fake news e pós-verdades), é importante desenvolver processos de confiabilidade informacional e, para tanto, a apreensão de conceitos epistemológicos e reflexões filosóficas sobre a informação se mostra fundamental. Nesse sentido, o trabalho de Luciano Floridi tem muito a colaborar, na busca de fundamentos a partir dos quais se possam dirigir trajetos de pesquisa e investigação.

\section{Referências}

ADAMS, Frederick. The informational turn in philosophy. Minds and Machines, [S. l.], v. 13, n. 4, p. 471-501, 2003.

CASTELLS, Manuel. A sociedade em rede. São Paulo: Paz e Terra, 1999. 
CERVO, Amado Luiz; BERVIAN, Pedro Alcino; SILVA, Roberto da. Metodologia cientifica. 6. ed. São Paulo: Pearson Prentice Hall, 2007.

CORNELIUS, Ian. Information and its philosophy. Library Trends, [S. l.], v. 52, n. 3, p. 377-386, 2004.

FLORIDI, Luciano. About: biography. 2020. Disponível em:

http://www.philosophyofinformation.net/about/. Acesso em: 28 jan. 2020.

FLORIDI, Luciano. Biblioteconomia e Ciência da Informação (BCI) como filosofia da informação aplicada: uma reavaliação. InCID: Revista de Ciência da Informação e Documentação, Ribeirão Preto, v. 1, n. 2, p. 37-47, jul./dez. 2010 .

FLORIDI, Luciano. Information: a very short introduction. Oxford: Oxford University Press, 2010.

FLORIDI, Luciano. Research: the tetralogy project. 2020. Disponível em: http://www.philosophyofinformation.net/research/. Acesso em: 28 jan. 2020

FLORIDI, Luciano. The philosophy of information. Oxford: Oxford University Press, 2011.

FLORIDI, Luciano. What is the Philosophy of Information? Metaphilosophy, New Haven, v. 33, n. 1-2, p. 123-145, jan. 2002.

FRANCELIN, Marivalde Moacir; PELLEGATTI, Caio. Filosofia da Informação: reflexos e reflexões. Transinformação, Campinas, v. 16, n. 2, p. 123-132, maio/ago. 2004.

GONZALEZ DE GÓMEZ, Maria Nelida. A análises das citações precisa de uma teoria ou da filosofia da ciência? Informação \& Sociedade, João Pessoa, v. 27, n. 2, 2017.

GONZALEZ DE GÓMEZ, Maria Nelida. Luciano Floridi e os problemas filosóficos da informação: da repres entação à modelização. InCID: Revista de Ciência da Informação e Documentação, Ribeirão Preto, v. 4, n. 1, p. 3-25, jan./jun. 2013.

LEITE, Leonardo Ripoll Tavares. Confiabilidade informacional: a Filosofia da Informação e o desenvolvimento da leitura crítica no ambiente virtual. Dissertação (Mestrado) - Universidade do Estado de Santa Catarina, Centro de Ciências Humanas e da Educação, Programa de Pós-Graduação em Gestão de Unidades de Informação, Florianópolis, 2018.

LEITE, Leonardo Ripoll Tavares; MATOS, José Claudio Morelli. Zumbificação da informação: a desinformação e o caos informacional. RBBD: Revista 
Brasileira de Biblioteconomia e Documentação, São Paulo, v. 13, p. 2334-2349, dez. 2017.

LÉVY, Pierre. Cibercultura. 3. ed. São Paulo: Ed. 34, 2010.

LIMA, Daniel Almeida; GOMES, Henriette Ferreira. Epistemologia social e filosofia da informação: um possível diálogo entre Jesse Shera e Luciano Floridi. Biblionline, João Pessoa, v. 12, n. 4, p. 25-41, 2016.

MATHEUS, R. F. Rafael capurro e a filosofia da informação: abordagens, conceitos e metodologias de pesquisa para a ciência da informação.

Perspectivas em Ciência da Informação, Belo Horizonte, v. 10, n. 2, p. 140$165,2005$.

MATTELART, Armand. Sociedade do conhecimento e controle da informação e da comunicação. In: ENCONTRO LATINO DE ECONOMIA POLÍTICA DA INFORMAÇÃ̃, COMUNICAÇÃO E CULTURA, 5., 2005, Salvador. Anais [...]. Salvador: UFBA, 2005. p. 1-22.

MOSTAFA, S. P. Epistemologia ou filosofia da ciência da informação?. Informação \& Sociedade: Estudos, João Pessoa, v. 20, n. 3, p. 65-73, 2010.

RABELLO, Rodrigo. Noções de sujeito em modelos teóricos na Ciência da Informação: do enfoque no sistema a consideração da agencia em contexto. Informação \& Sociedade, João Pessoa, v. 23, n. 3, p. 57-71, 2013.

REVOREDO, Túlio de Morais. A Filosofia da informação na ciência da informação brasileira: uma análise da repercussão da teoria de Luciano Floridi. 2015. 118 f. Dissertação (Mestrado) - Curso de Programa de Pósgraduação em Ciência da Informação, Departamento de Ciência da Informação, Universidade Federal de Pernambuco, Recife, 2015.

REVOREDO, Túlio de Morais. A filosofia da informação no Brasil: uma representação dos artigos científicos produzidos entre os anos de 1972 a 2013.

In: ENCONTRO NACIONAL DE PESQUISA EM CIÊNCIA DA INFORMAÇÃO, 15., 2014, Belo Horizonte. Anais [...]. Belo Horizonte: ECI/UFMG, 2014. p. 312-318.

ROBREDO, Jaime. Filosofia e informação?:reflexões. Revista IberoAmericana de Ciência da Informação, Brasília, v. 4, n. 2, p. 1-39, ago./dez.2011.

SALCEDO, Diego Andres; REVOREDO, Túlio de Morais. O estado da arte da Filosofia da Informação na Ciência da Informação Brasileira. DataGramaZero, Rio de Janeiro, v. 14, n. 6, dez. 2013.

SALDANHA, Gustavo Silva. Maravilhoso informacional: crítica da filosofia da informação sob uma reflexão hermenêutica entre medievo e modernidade. 
Logeion: filosofia da informação, Rio de Janeiro, v. 1 n. 1, p. 20-42, ago./fev. 2014a.

SALDANHA, Gustavo Silva. O demônio da brecha da linguagem: Capurro, ética e filosofia da informação na Alemanha dividida. In: ENCONTRO NACIONAL DE PESQUISA EM CIÊNCIA DA INFORMAÇÃO, 15., 2014b, Belo Horizonte. Anais [...] . Belo Horizonte: ECI/UFMG, 2014. p. 106-124.

SALDANHA, Gustavo Silva. O imperativo mimético: a filosofia da informação e o caminho da quinta imitação. In: ENCONTRO NACIONAL DE PESQUISA EM CIÊNCIA DA INFORMAÇÃO, 12., 2011, Brasília. Anais [...] . Brasília: ANCIB, 2011. p. 56-71.

SOUZA, Sebastião de. Fundamentos filosóficos da Biblioteconomia. Revista de Biblioteconomia de Brasília, Brasília, v. 14, n. 2, jul./dez. 1986, p. 189-196.

SUAVE, Aline Laureano; ALBUQUERQUE, Ana Cristina. Ciência da Informação e Filosofia da Informação: reflexões e relações. In: ENCONTRO NACIONAL DE PESQUISA EM CIÊNCIA DA INFORMAÇÃO, 19., 2018, Londrina. Anais [...] Londrina: Universidade Estadual de Londrina, 2018. p. 409-418.

\title{
Disinformation and semantic information: the Philosophy of Information and the contribution of Luciano Floridi's thought to information reliability
}

\begin{abstract}
This article presents the Philosophy of Information, a theoretical and methodological approach developed by Luciano Floridi as proper epistemological foundation to information society, a term presented as representative of the current social and historical scenario. Through a study of exploratory character, this paper discusses crucial concepts of Floridi's thought, such as semantic information and information veridicality, to demonstrate how the author tackles the issue of disinformation. Finally, Floridi's ideas are related to the notion of information reliability a concept to be developed in contemporary context in order to combat disinformation.
\end{abstract}

Keywords: Philosophy of information. Luciano Floridi. Semantic information. Disinformation. Information Reliability. 
${ }^{1}$ Artigo desenvolvido a partir de parte da dissertação: Confiabilidade informacional: a Filosofia da Informação e o desenvolvimento da leitura crítica no ambiente virtual (LEITE, 2018).

${ }^{2}$ No original: "The information society is like a tree that has been growing its far-reaching branches much more widely, hastily, and chaotically than its conceptual, ethical, and cultural roots."

${ }^{3}$ No original: "[...] in order to expand and reinforce our conceptual understanding of our information age, of its nature, of its less visible implications, and of its impact on human and environmental welfare, and thus give ourselves a chance to anticipate difficulties, identify opportunities, and resolve problems."

${ }^{4}$ No original: "[...] the information society can be seen as the most recent, although not definitive, stage in a wider semantic process that makes the mental world increasingly part of, if not the environment in which more and more people tend to live."

${ }^{5}$ No original: "[...] the philosophical field concerned with (a) the critical investigation of the conceptual nature and basic principles of information, including its dynamics, utilisation, and sciences, and (b) the elaboration and application of information-theoretic and computational methodologies to philosophical problems."

${ }^{6}$ No original: "It analyses problems in order to design solutions. It is a thriving new area of research, at the crossroads of epistemology, metaphysics, logic, philosophy of science, semantics, and ethics."

${ }^{7}$ No original: "From an environmental perspective, PI is prescriptive about, and legislates on, what may count as information, and how information should be adequately created, processed, managed, and used."

${ }^{8}$ No original: “[...] to develop not a unified theory of information but ratheran integrated family of theories that analyse, evaluate, and explain the various principles and concepts of information, their dynamics and utilisation, with special attention to systemic issues arising from different contexts of application and interconnections with other key concepts in philosophy, such as being, knowledge, truth, life, and meaning.".

9 Outros artigos (como, por exemplo, Saldanha (2014a; 2014b) e Elias (2011)) mencionam discussões sobre a 'filosofia da informação', porém, partindo de outros pressupostos teóricos, sem remeter a Luciano Floridi. Além disso, em 2014 também foi criado um periódico denominado Logeion: filosofia da informação (http://revista.ibict.br/fiinf) pelo grupo de pesquisa Filosofia e política de informação, do Instituto Brasileiro de Informação em Ciência e Tecnologia (IBICT)

${ }^{10}$ Floridi não utiliza a palavra confiabilidade em seus trabalhos, porém, desenvolve teorias buscando a relação da informação com o confiável, o verdadeiro, o verídico (truthful, veridical). ${ }^{11}$ Apesar de a tradução de truthful para o português remeter também à palavra "verdadeiro", Floridi (2011, p. 105, tradução nossa, grifo do autor) explica que ela deve ser entendida como algo que está '[...] 'fornecendo conteúdos verdadeiros sobre um sistema em particular'. É preferível falar 'dado confiável' [no original, 'truthful data'] do que 'dado verdadeiro' [no original, 'true data'] porque o dado em questão pode não ser linguístico, e um mapa, por exemplo, é mais 'confiável' do que 'verdadeiro'; e porque 'dado verdadeiro' pode dar origem a uma confusão, como se se estivesse enfatizando a natureza genuína do dado em questão, não a sua veracidade [no original, 'veridicality']." 